\title{
Quaternary Pattern of Freshwater Fishes in Europe: Comparative Phylogeography and Conservation Perspective
}

\author{
Caroline Costedoat* and André Gilles*
}

Aix-Marseille Université,UMR 6116, Equipe Persistance et Evolution de la Biodiversité, 3 place Victor Hugo 13331 Marseille, France

\begin{abstract}
The phylogeographic studies of unrelated species that share overlapping distributions lead to new perspectives. Indeed, if different species with similar distributions shared the same phylogeographic pattern, then a common extrinsic cause could be proposed, involving some important issues for species conservation. Considering different mitochondrial studies of European freshwater fishes (threatened or not), it will be possible to perform such a comparative phylogeographic analyses. However, we illustrated how similar mitochondrial patterns can be due to different demographic models or evolutionary scenarios inducing numerous pitfalls. In this review, we present some major theoretical and practical challenges on phylogeography that need to be overcome before the inference of a global scenario. More than the evolution of the phylogeography discipline, estimation of the history of populations/species and their relationships is one of the most important challenges for conservation managers.
\end{abstract}

\section{INTRODUCTION}

Phylogeography is an emerging field that analyses the geographical distribution of genealogical lineages. During the last two decades a large number of phylogeographic studies have been published which have contributed significantly to our understanding of Pleistocene population dynamics (4260 matches using the key word "phylogeography" in WoS). However, few of the original studies investigated more than one species, usually comprising a limited geographic and taxonomic range, and few systematic attempts have been made to extract large scale general patterns via a comparative meta-analysis. Previous phylogeographic meta-analysis of regional faunas such as Europe [1-3] have been carried out at a time when only a limited number of comparable studies were available compromising the generality of the inferred patterns. Meanwhile, it has become clear that many species do not fit previously recognised patterns and new hypotheses have been proposed since $[4,5]$ and statistical meta-analyses has been increasingly applied $[6,7]$.

Hewitt suggested that European rivers had often been colonized via the rivers Danube and the Dniepr from a Pontic refugium [4]. Taking into account the example of perch (Perca fluviatilis) and chub (Leuciscus cephalus), the author pointed out that it could be interesting to illustrate this new paradigm. Indeed, each one of these two fish species is constituted by several lineages dating from 2 Myr, which seemed to indicate that the colonization of Western Europe occurred in relatively recent interglacial and postglacial expansions from several major refugia.

Other studies could now be added to investigate the evolutionary landscape of freshwater fishes. Such informa-

*Address correspondence to these authors at the Aix-Marseille Université, UMR 6116, Equipe Persistance et Evolution de la Biodiversité, 3 place Victor Hugo 13331 Marseille, France; E-mail: caroline.costedoat@univprovence.fr; andre.gilles@univ-provence.fr tion is relevant to conservation biology because it will facilitate the identification of management units for individual species as well as regional faunas and the recognition of cryptic invasions or species translocations. This paper reviews the phylogeography of 14 freshwater fish species deemed to be representative of the main colonization patterns in Europe in order to illustrate a potential methodological bias for comparative meta-analysis. We identify and explain seven crucial points that need to be considered before inferring universal biological patterns and processes and lead us to discuss the use of such global knowledge of the past in the application of comparative phylogeography to key conservation issues. Through different examples based on freshwater species, we illustrate and discuss problems associated with these different methods in the estimation of divergence time in a context of meta analysis.

A range of DNA techniques, combined with new analytical methods and recent palaeoclimatic and geological studies are providing important insight into the distribution of genetic diversity around the globe, and how it evolved. In this review, we highlight that the study of climate induced Quaternary patterns of dispersal, isolation and range shift holds great promise for addressing emerging issues in biodiversity management for the future. Indeed, these different studies allowed the determination of reference populations for which future change can be tested (e.g. influence of climate change, conservation strategies, biological invasions...). In this context, comparative phylogeo-graphy perspectives (with their spatial and temporal approaches) present key on-going issues of global conser-vation.

\section{PHYLOGEOGRAPHIC PATTERNS}

\subsection{Family: Lotidae}

\section{Lota lota (Linnaeus, 1758)}

The fossil data suggest that Lota lota was present in Europe at the beginning of the Pliocene around 5 million 
years ago [in 8]. Based on the analysis of $663 \mathrm{bp}$ of the cytochrome $b$ gene from 41 locations and an assumed divergence rate of $2 \%$ per million years van Houdt et al. [8] came to the following conclusions: Burbot colonized North American across Bering Strait during early Pleistocene. Subsequently, the Eurasian population experienced a drastic decline and was possibly restricted to a small geographical area in Eastern or Central Asia. Around $300 \mathrm{kyr}$ ago L. lota expanded its range again and colonized Europe (Fig. 1a). During subsequent glacial cycles, European burbot populations retreated to two glacial refugia resulting in two genetic lineages with a distinct geographic distribution. A potential refugium in France or Italy contributed to the postglacial colonization of Western and Central Europe whereas Eastern Europe was colonized from a refugium in the Pontic region. Furthermore, Northern and Northeastern Europe were colonized from a refugium in Central Asia.

\subsection{Family: Percidae}

\section{Perca fluviatilis (Linnaeus, 1758)}

Nesbo et al. [9] sampled 34 populations around Europe plus one in Siberia and used the mitochondrial control region as a molecular marker. They used a divergence rate of $2 \%$ and of $6 \%$ per million years because of the difference encountered in the literature.

Four genetic lineages of Perca fluviatilis with distinct geographic distribution were identified. These lineages diverged quite recently with a most recent common ancestor around 0.19 and $0.57 \mathrm{Myr}$ ago indicating a severe range contraction during the mid-late Pleistocene. The lineage with the largest distribution was found across Western and Central Europe as well as in Italy, Britain and Southern Scandinavia. The other three lineages had more restricted distributions: the most divergent lineage showed a mainly Balkans distribution, but was also found in the river Danube in Austria. Another lineage was found in the drainages east of the river Danube and Vistula, and one lineage was mainly found in Norway. All lineages apart from the Balkan group were found in Southern Sweden and Finland indicating secondary contact after post-glacial colonization from four different refugia. The species colonization in the direction of the North and West of Europe seemed to originate from three main refuges (R2, R3, R4), whereas R1 presumably served as a founder population for present perch lineages in Europe after one of the earlier Pleistocene glaciations (Fig. 1b).

\subsection{Family: Cottidae \\ Cottus gobio (Linnaeus, 1758)}

The fossil record indicates that Cottus was present in Europe during the Pliocene. A number of phylogeographic studies addressed the Pleistocene history of Cottus gobio using mainly the control region [10-13]. However, different divergence rates were used by different authors ranging from $1 \%$ to $9 \%$ per million years to better coincide with the geological events and with the results obtained previously on allozymes respectively. Cottus gobio was defined as a cold tolerant species. The first colonization of Central Europe originated possibly from the lower Danube. At the end of the Pliocene, one of the central populations reached the North Sea and allowed the colonization of the Atlantic networks via the coasts.
Six haplotype lineages were observed [10]. Group I was the sister group to all the others. Volckaert et al. [11] identified another clade (VII) (Fig. 1c). The authors found a low haplotype diversity. Pleistocene glacial cycles seemed to have only limited influence on the population structure of Cottus gobio in Europe. Slechtova et al. [13] explained that the species probably crossed the Dinaric Alps several times. This new result allowed them to consider another hypothesis to explain relationships between different populations distributed on the two sides of mountains in Europe and potential gene flow between them. Hybridization was observed between an eastern group and western group in Northern Scandinavia [12].

\subsection{Family: Salmonidae \\ Thymallus thymallus (Linnaeus, 1758)}

The three following studies [14-16] used the control region as a molecular marker, however in the first study the authors used a divergence rate of $1 \%$ per million years whereas the others used a rate of $2 \%$ per million years. Five haplotypic groups were observed (Fig. 1d). They presented strong genetic differentiation suggesting that the species was probably present in Europe before the Pleistocene. For this species too, the Danube basin defined a main refuge zone but the colonization of the North of Europe from this refuge was again under question [15]. The divergence of the Loire suggests the presence of old glacial refuge with no genetic link with the Rhone or the Rhine. However, even if the relationships between the different groups remain uncertain there is a significant divergence between populations from the Elbe basin and those of the Danube and the Rhine basins (650 000+/-150 000; Gum et al. [15]), as well as, more globally, between the lineages from the South and those from the North. Hybridization between Rhine and Rhone lineages has been identified. Morphological variations not described until now for the populations from Croatia, Serbia and Romania could have been the result of a stronger genetic variability. Furthermore, human-mediated transfers posed considerable problems for phylogeographic reconstruction of this species.

\subsection{Family: Cobitidae}

\section{Cobitis taenia (Linnaeus, 1758)}

Culling et al. [17] analyzed 320 individuals sampled across Central and Eastern Europe and used the cytochrome $b$ as a molecular marker. The datation were performed by two approaches i) the calibration of the cytochrome $b$ that corresponds to $0.84 \%$ sequence divergence per million years (calculating using HKY $85+$ gamma) for the Cobitis genus based upon the opening of the Strait of Gibraltar after the Messinian salinity crisis (5.5 million years ago); ii) the average distance of the members of a given clade $(\rho)$ was inferred from the most recent common ancestor (MRCA) of the clade as expressed in the number of mutation steps, the absolute timing calculated by multiplying the observed values by a mutation rate of 0.0042 mutations per site per million years.

The Ponto-Caspian area provided shelter for $C$. taenia in Europe during glaciations. According to the distribution of the major clades, several isolated areas seem to have harboured $C$. taenia refugial populations during the glacial 
periods. For clade 2.4 the lower Southern Bug river was likely such a place and the Crimean peninsula, lower Dnieper river and/or rivers east to the Dnieper harboured clade 2-3. The distribution of clade $2-1$ is mostly restricted to areas more to the northwest. The author hypothesized that the unique distribution of clade 2-3 in France may also indicate a western refugium (Fig. 1e).

\subsection{Family: Balitoridae}

\section{Barbatula barbatula (Linnaeus, 1758)}

Sediva et al. [18] studied 77 Barbatula barbatula from the major Danube tributaries and 52 from non-Danubian locations and amplified a portion of the cytochrome $b$ gene. They used two calibration points (fossil records and geological events) for estimating divergence dates and declared that their results should be viewed with caution.

The authors defined five highly divergent lineages of Pre-Pleistocene age and suggested lineages extended from $7.0 \%$ to $13.4 \%$. During the warmer period in the Miocene, areas surrounding the Alps and Carpathians served as mountainous refuges for cold-water adapted fish and promoted diversification of its populations and from these refuges colonization of the emerging Danube river system have taken place following the retreat of the Central Parathethys (Fig. 1f). The authors also favored the hypotheses that the Pleistocene glaciations promoted the dispersal and mixing of populations through the lowland. Possible hybridization between the lineages in the contact zone (particularly in the case of the Eastern Caspian lineages) cannot be excluded.

\subsection{Family: Cyprinidae}

\section{a) Barbus barbus (Linnaeus, 1758) and Barbus meridionalis (Risso 1826)}

Phylogeographic studies of the genus Barbus were based on the cytochrome $b$ gene [19-27]. Globally, the authors used a substitution rate ranging from $0.72 \%$ to $0.76 \%$ per site per million years.

One of the particularities of the Barbus genus is the presence of diploids, tetraploids and hexaploids. This characteristic induces an additional difficulty concerning the resolution of the taxa relationships when nuclear genome was considered.

Two main lineages could be differentiated into the Barbus barbus: lineage I on the South and East of the Black Sea, lineage II everywhere else in its repartition area in Europe (Fig. 1g). This last lineage was issued from only one refuge zone on the Danube basin. Barbus barbus was not present nor on the Mediterranean peninsulas neither on the Central region of the Balkans where it was replaced by sister species B. haasi (Spain), B. plebejus and B. tyberinus (Italia) and B. macedonicus (Central Balkans). The two species $B$. meridionalis and B. haasi hybridized in the North of Spain. All these species presented diagnosable morphological differences. B. meridionalis was known from the Miocene in the South of France (fossil records) and seemed to be the first species of the Barbus genus to arrive on the European Continent. However, no cladistic studies could confirm this relationship, and we are so in a context of "global" morphological resemblance. Indeed, it is difficult to know if the previously cited fossil was either a representative of the sister group of the current Barbus European lineage common ancestor or a representative of the common ancestor lineage or a representative of the anagenetic lineage of Barbus meridionalis.

B. barbus and B. meriodionalis hybridized in the South of France (Lergue river) but the contemporaneous dating of this phenomenon was not demonstrated [28].

\section{b) Leuciscus cephalus (Linnaeus, 1758) or Squalius cephalus (Linnaeus, 1758)}

Durand et al. [29-31], Sanjur et al. [32] (2003) analyzed the cytochrome $b$ gene. The authors used different divergence rates to appreciate the divergence time between the lineages (from $1 \%$ to $2.8 \%$ per million years, rates used in Orti et al. [33] for the sticklebacks, Gasterosteus aculeatus).

Four main lineages could be defined with the mitochondrial analyses representing four large geographic regions, two Mediterranean zones (Adriatic lineage and Aegean lineage) and two Central European zones (lineage from the East and these from the West), (Fig. 1h). This geographic distribution as well as the genetic divergence between the lineages (from $5.2 \%$ to $7.89 \%$ ) indicated the presence of four refuge zones (Adriatic part of the Balkans, East of Greece, South of Danube and the rim of the Black Sea and of the Caspian Sea).

There are few crosses between lineages, the only ones were in Greece where Danubian haplotypes were found and denoted hybridization event. The Elbe basin represents the limit between the Eastern and Western lineages. Contrary to these two Central Europe lineages that seemed to be strongly influenced by the Danubian "pool", the South lineage (Mediterranean) presented a strong endemism. Marine regressions and river captures during the glaciations could be responsible to the three lineages split of the Balkan region: the Adriatic lineage, the Aegean lineage and the part of the Danubian lineage in the centre of this zone. In the literature, the L. cephalus complex was defined by numerous species.

\section{c) Leuciscus souffia (Risso, 1826) or Telestes souffia (Risso, 1827)}

Three mitochondrial genes have been the focus of attention [34-37]: the $16 \mathrm{~S} \mathrm{rDNA}$, for which a divergence rate of $0.7 \%$ per million years was used; the control region, with the use of a substitution rate of $1 \%$ or $2 \%$ per million years (the use of a $1 \%$ rate allowing to be more congruent with geological and climatic data but also with other species); and the cytochrome $b$ for which the rate used was $1 \%$ per million years.

Under the Leuciscus souffia name, three sub-species are grouped: L.s.souffia, L.s.agassizi and L.s.muticellus. However, the relationship between these lineages was not clear and the phylogenetic signal was different in function of the considered marker used (allozymes, mtDNA or morphology). More than a similar morphology, L.s.souffia and L.s.agassizi shared the same enzymatic polymorphism and the same mitochondrial haplogroup (based on the $16 \mathrm{~S}$ rDNA; with the use of $0.7 \%$ of nucleotidic divergence per million years) and so were considered until now as only one unit, except for some specimens that presented introgressed 
mitochondrial genome from muticellus. These two clades (lineages souffia+agassizi and muticellus) presented 5.6\% of divergence (based on control region, $1 \%$ of divergence per millions years), some authors talked about an Italian lineage and an Alpine lineage.

L.s.muticellus (Italian sub-species), was also divided into two geographically distinct lineages. The Alpine lineage is divided into two lineages: one defined by the Rhone basin and the Var haplotypes, and the other defined by the haplotypes from the Danube and the Rhine. So, two hybrid zones were defined in the Mediterranean Alps and in the Soca basin, (Fig. 1i). The relationship between these two lineages and other sister species is ambiguous and these three lineages seemed to be differentiated at the same moment. The presence of the species in Central Europe was anterior to the Pleistocene glacial cycles and the distribution of the species leads us to assume two main refuge zones (in Italy and in the Danube basin), the colonization of the Rhine system occurring more recently. More than the impact of Pleistocene glaciations on the distribution of the lineages, the Mediterranean zone was also influenced by the "Lago Mare" phase of the Mediterranean Sea [38]. Indeed, the drying out of the sea and the following "freshwater" phase would be at the origin of the colonization of primary species leading to a high diversification and an important rate of endemism.

\section{d) Leuciscus leuciscus (Linnaeus, 1758)}

Despite a very large distribution area the Leuciscus leuciscus was genetically is poorlyly understood. The literature is not homogeneous and different nomenclatures exist.

Recently, Costedoat et al. [39] studied 663 individuals from 31 populations all around the distribution area and analyzed three mitochondrial genes (16S rDNA, control region and cytochrome $b$ ) to evaluate the species structure. The authors defined two main clades split into five lineages (Fig. 1j). The two clades presented $6 \%$ of divergence (based on the cytochrome $b$ and the use of a substitution rate of $1 \%$ per million years).

The first clade (clade A) is divided in three lineages: lineage I corresponding to the Eastern Europe lineage (Danube, Volga basins...), and lineage II with England and Rhine populations. The second clade (clade B) is defined by three lineages: lineage III (Rhone basin), lineage IV (LoireAllier basin and Britain) and lineage V (West of France populations and Coastal Mediterranean rivers except the Vidourle River). Into each clade (clade $A$ and $B$ ), the divergence between the lineages was about $3 \%$. Danube basin also represented a main refuge zone for this species but other minor refuges were defined (Moselle basin, Rhone basin, Adour-Garonne basin and Loire basin). The strong divergence between the different lineages contradicts the hypothesis in which the colonization of Western Europe was initiated quite recently (i.e. during the Pleistocene) from the Balkans region [4]. Surprisingly, the authors also described hybridization between lineage I and Leuciscus idus species

e) Chondrostoma toxostoma toxostoma (Vallot, 1836) and Chondrostoma nasus nasus (Linneaus, 1758)

Under the Chondrostoma toxostoma name, three subspecies could be differentiated: C.t.toxostoma (endemic of
Adour-Garonne and Rhone basins), C.t.miegii and C.t.turiense (North of Spain). These sub-species split definition depends on the considered authors and some preferred to define them as two or three different species [40, 41]. The toxostoma lineages diverged about $3 \mathrm{My}$, in the Pliocene. No geological data are available to explain the connection between Iberian basins and the Rhone basin during the Pliocene. The connection between the Rhone and the Ebro rivers could only have been possible during the Messinian when the Rhone discharged into the Mediterranean basin [41], Fig. (1k).

Relations into the "nasus" lineage are simpler [40, 41] with four well-established species: Chondrostoma nasus, C.holmwoodi, C.vardarensis and C.prespensis. However, Nelva [42] and Durand et al. [40] differentiated C.n.nasus from C.n.angorensis and C.n.borystenicum. The "nasus" lineage is present in the Mesopotamian area and has been isolated during the upper Miocene-Pliocene. The differentiation of C. nasus from its sister species (C.holmwoodi) took place in the middle Pliocene [41]. The lineage must have invaded Greece through Pliocenic river captures whereas it dispersed from the Danube and its surrounding and probably invaded Western Europe (through the Rhine) during the Pleistocene [43].

The genetic divergence between C.t.toxostoma and C.n.nasus is about 10 millions years ([41]; based on the entire cytochrome $b$ with the use of a substitution rate of $1 \%$ per millions years). However, Gilles et al. [34], Costedoat et al. $[44,45]$ demonstrated that these important mitochondrial divergences did not reflect potential genome incompatibilities and the recent colonization of the C.n.nasus into the Rhone basin lead to the definition of hybrid zones with C.t.toxostoma (Fig. 1k).

\section{f) Rhodeus complex (Bloch, 1782)}

Bohlen et al. [46] studied the phylogeography of the Rhodeus complex with the use of the cytochrome $b$ gene and a mutation rate of $1.05 \%$ per million years.

Five lineages were identified: lineage I ( $R$. sericeus, Amur), lineage II ( $R$. meridionalis, Greece), lineage III $(R$. amarus "Western", Danube, Elbe, Odra, Rhine), lineage IV $(R$. colchicus, Caucasus) and lineage V ( $R$. amarus "Eastern", Vistula to Volga). The differentiation of the four lineages (II-V), occurred much later than the separation from East Asia. Indeed, the separation of the Aegean drainage populations from the non-Mediterranean populations can be dated to about 1.8 Myr (Pliocene); while the trichotomy of the lineages III to V was calculated back to 1.1-1.5 Myr. The authors suggested that lineage III had its glacial refuge in the Western Black Sea drainage, while the lineage $\mathrm{V}$ found refuge in the Danube drainage. Some population presented some particular haplotype composition owing to their geographical localization (e.g the Lake Vierer populations presented mixed origin (III/V), and the Saone river population presented haplotypes from group V; Fig. 11). The population in the Aegean river Vardar is a long-term isolated independent lineage, (Fig. 11).

\subsection{Phylogeographic Patterns Discussion}

Globally, as illustrated by the different previous examples, phylogeographic studies in Western Europe have 

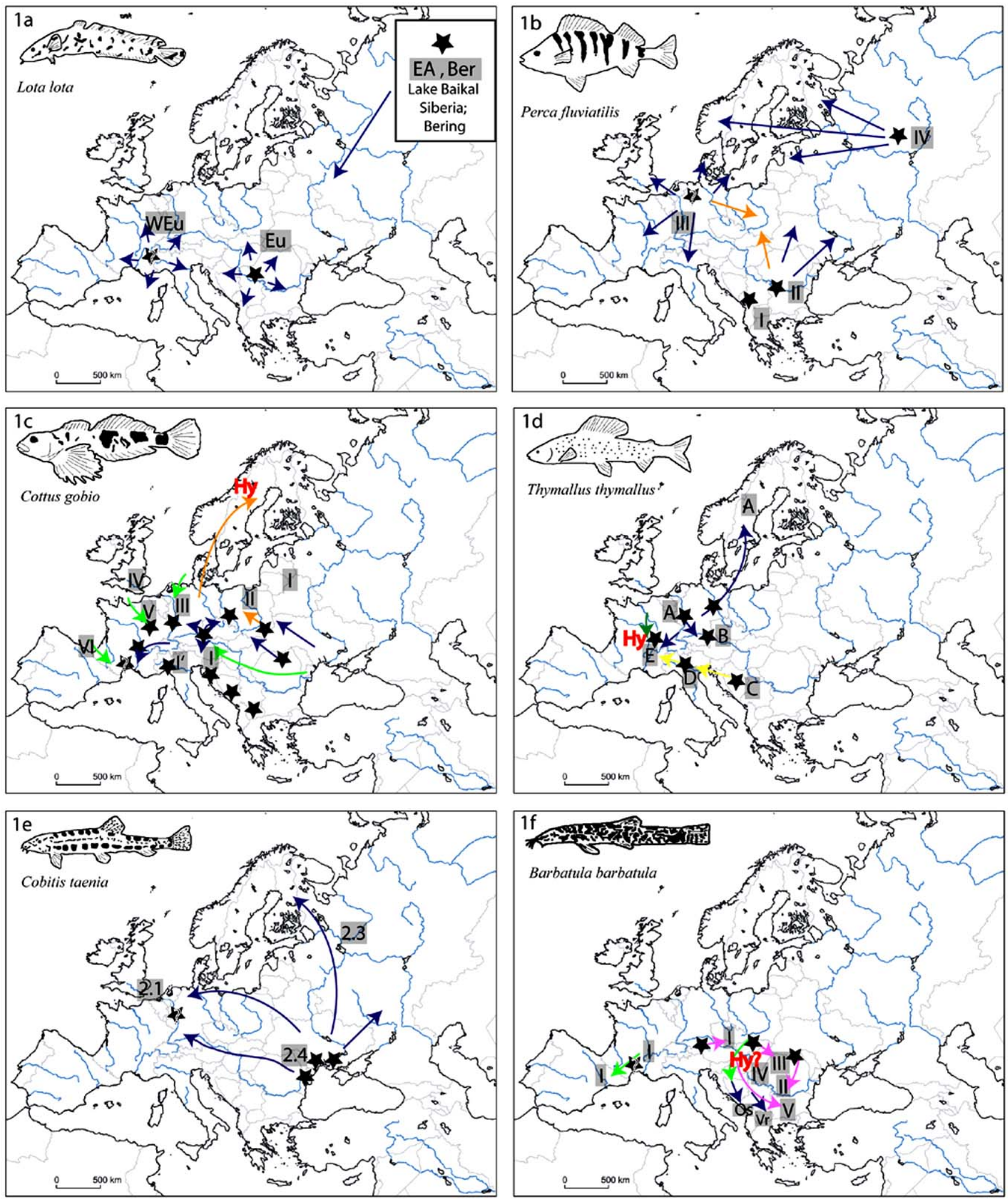
Fig. (1). Contd.....
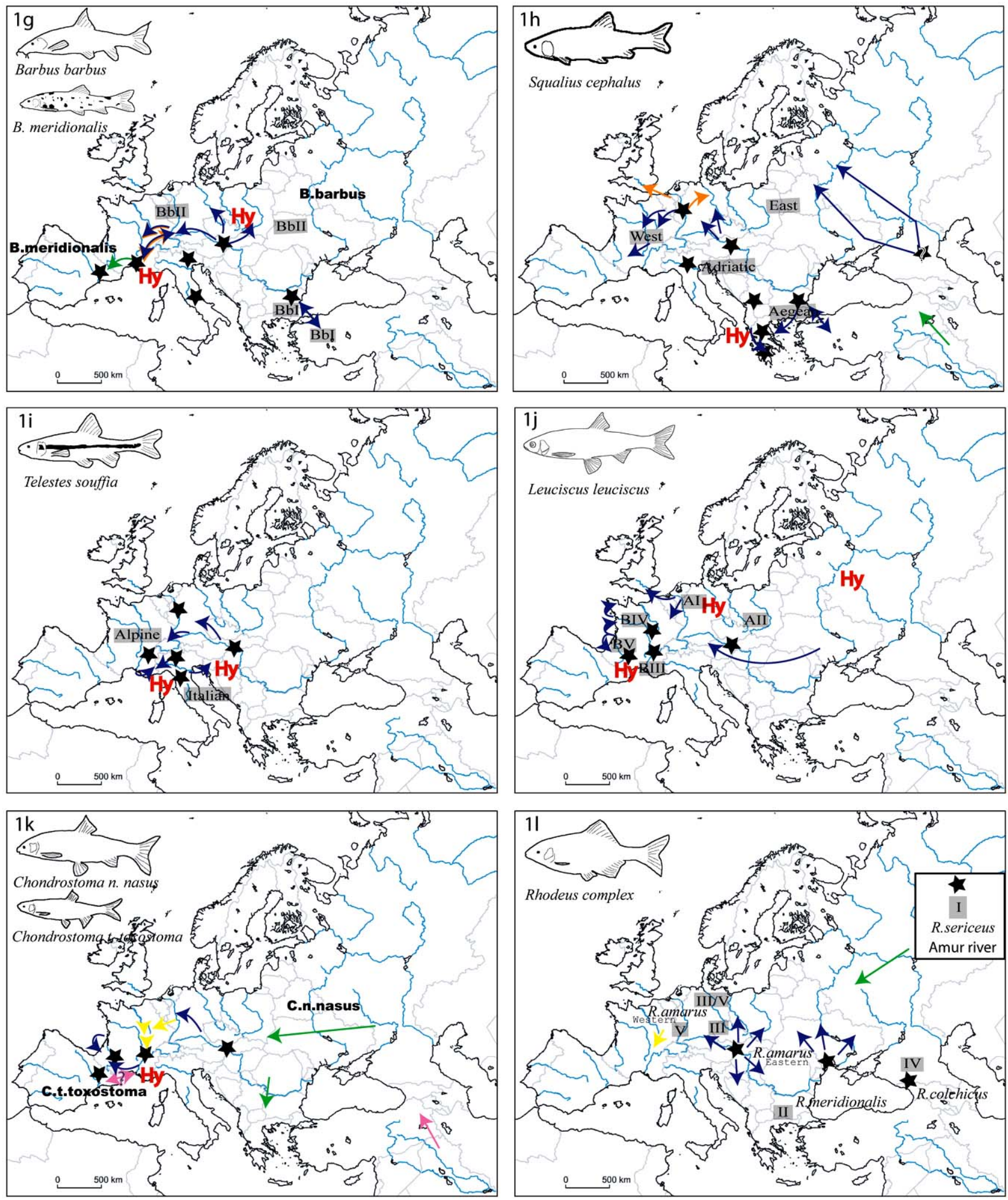

Fig. (1). Colonisation pattern of European cyprinids species. a) Lota lota; b) Perca fluviatilis; c) Cottus gobio; d) Thymallus thymallus; e) Cobitis taenia; f) Barbatula barbatula; g) Barbus barbus \& B.meridionalis; h) Squalius cephalus; i) Telestes souffia; j) Leuciscus leuciscus; k) Chondrostoma nasus nasus \& C. toxostoma toxostoma; l) Rhodeus complex. Pink arrow: Miocene event; green arrow: Pliocene event; blue arrow: Pleistocene event; orange arrow: Holocene; Yellow arrow: contemporaneous event. Black star: glacial refuge. Hy: Hybridization/introgression phenomenon. The lineage names are in grey tint. Question mark indicates uncertain zone or event. 
mainly used the glacial refuge hypothesis to interpret results of geographical structure and gene flow [9, 14]. In this way, the Balkans are presented as the major source of colonization for all animal species in Eastern Europe and for many species in Western Europe [2]. In particular, the temperate freshwater fishes seem to have colonized European rivers from the Black Sea through rivers such as the Danube and the Dniepr [4]. As presented by Hewitt [4], these geographical patterns "'perhaps deserve a new paradigm', partly illustrated in the different maps. Indeed, the colonization of Western Europe is presented as a relatively recent event characterized by low haplotype diversity of species such as Leuciscus cephalus [29], Barbus barbus [24], Perca fluviatilis [9], Chondrostoma nasus nasus [47]. The pattern of colonization observed for Cottus gobio [48] is considered to be exceptions, Cottus gobio being cold-adapted. Due to severe climatic oscillations, temperate species are expected to have evolved through many contractions and range expansions, which are expected to have left signatures in the geographical distribution and genetic diversity of extant populations [49]. Refugial populations are therefore expected to have accumulated genetic differences that may be used as genetic markers to trace expansion routes [50] and genetic variability is expected to be higher in refugial populations than in recent populations.

\section{Methodological Bias}

We argue that there is now sufficient data available to conduct rigorous meta-analyses for many regional faunas. Such an approach will not only reveal powerful insights in Pleistocene range shifts [51] and provide important management information [52] but will also generate new hypotheses. This is timely just as second generation markers such as microsatellites, SNP's, AFLPs and nuclear gene sequences are making their impression on this field [53-55] and new powerful statistical analysis tools become available [56-59]. However, taking into account information of different studies to infer a general pattern is not exempt of bias and we identified several potential problems concerning sampling, molecular data analysis and interpretation which need to be addressed before achieving such a goal.

Phylogeographic field difficulties come from the fact that the past distribution of species was not necessarily the same as the current one [7, 49] and the "coalescence" of patterns (from what is observed today to what was the species distribution in the past) can be undertaken only via indirect methods using diverse biological markers and a strong knowledge of geological events.

The "bias" that we met through our bibliographic research, resulted mainly from the temptation to generalize patterns and process to all biological models or gene and to infer biological history before testing if this generalization makes sense for the species or gene of interest.

Thus, the first problem arises from the confusion between genealogy and species history $[60,61]$, and could be directly link to the historic development of the Phylogeography as a formal discipline. Indeed, this discipline emerged with the introduction of mtDNA analyses to population genetic (and the conceptualization of the coalescent theory). Animal phylogeography is so dominated by mtDNA, while plant phylogeography is dominated by chloroplast (cp)DNA. For both plants and animals, however, other DNA sequences and marker systems are available, and there is an increasing

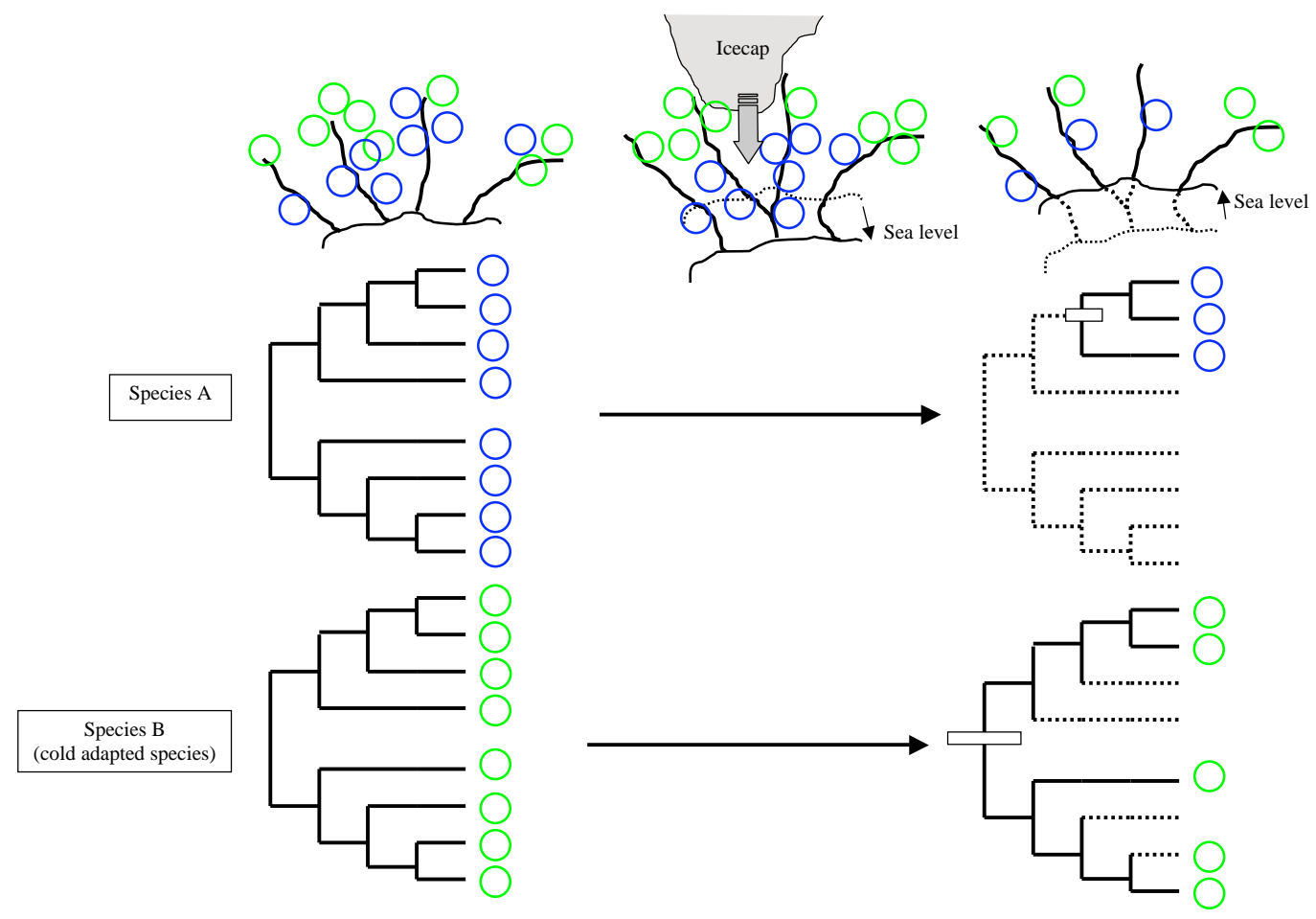

Fig. (2). Impact of unequal lineages sorting between two species. Example of glacial period phenomenon impacts on two species phylogenies (e.g. variation of the sea level, icecap development). The higher part of the scheme illustrates the geographic variation during glacial period. The lower part of the scheme summarised lineage sorting of two species (the first one non tolerant to cold temperature and the second one cold adapted), using phylogenetic representation. 
awareness of the rewards offered by these. Indeed, a single gene tree might not accurately reflect the history of a species [62], because of the presence of lineage sorting (e.g. Fig. 2), paralogous relationships, etc. Gene trees and species trees are often inconsistent and so the use of sequences from a single gene from various species to reconstruct the species tree can yield to an erroneous species tree even if the gene tree is absolutely correct. For deeper phylogenetic history, more "slowly" evolving sequences are needed, while for recent events, perhaps measured only in tens of thousands of years, more variable or more quickly evolving markers are required.Therefore independent markers verification represents the simplest solution to avoid misinterpretation [54].

The second difficulty arises from the dualism of morphology versus molecule. Once phylogeographical patterns have been established, it is interesting to map the character variation over these patterns, in order to make specific inferences about the evolutionary processes. One can think that this information does not concern phylogeographic area (which is originally defined to analyze the geographical distribution of genealogical lineages), but to reconstruct a population, subspecies or species phylogeographic history, one would ideally like to use a range of sequences but also any other information that help to provide a fuller and more reliable species history. In this context, we though that morphological study has its own place. Morphological and molecular divergence might not always be well correlated across taxa. Thus, the predefinition of species on morphological grounds can lead to a sampling bias [63]. Indeed, in a general way, specimens used for phylogeographic studies were collected solely on the basis of the species phenotypic description, and few authors analyze morphological characters to confirm the diversity of the "taxonomic entity" $[64,65]$. This problem could be exacerbated in the analyses of the morphological characters [66] and particularly the methodological choice of individual assignment using morphological data. A simple way to limit this sort of problem is to perform routinely the two approaches (morphology and molecular) in each study, notably to help to infer historical and geographical patterns.

The third difficulty is the presence of hybridization among lineages or phylogroups [45], (example illustrated in Fig. 3). Indeed, such a problem could not be only resolved using a unique marker as done by several studies when haplotypes belonging to two different lineages occurred in the same river. Furthermore, hybridization (and introgression) could erase some haplotypes leading to the underestimation of the lineage divergence. The easier way to decipher hybridization is first to use different markers (e.g. morphology plus mitochondrial gene plus nuclear gene). Furthermore, it is crucial for biologists that infer species history with their data not to forget hybridization as a possible pattern explanation. Indeed, even if now introgressive hybridization is considered as an evolutionary force, not all data analyses deal with. Considering methodological analyses, hybridization could be deciphered for example when adding haplotype networks to classical phylogenetic analyses (allowing to visualise alternative evolutionary ways). Hybridization is not considered in the major biological inference keys proposed by the different software's, but it is a statistical challenge not totally resolved today and effort as to be done in this direction.

The fourth difficulty arises from the ecological behavior of the species studied. Geographic distribution of sample sites is often not sufficiently concordant to assume that taxa were exposed to the same historic processes (example illustrated in Fig. 4). Indeed, a similar pattern of colonization could be found for two species that currently present an identical ecological behavior in spite of one of the species having had another behavior in the past. In an ecological point of view, the different Cyprinids species are all defined as stenohaline (primary species following Banarescu nomenclature [67]). This shared characteristic allowed the generalization of the potential impact of some geological events to all the representatives of the family (under the

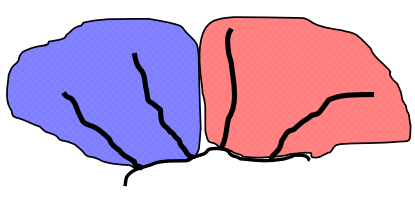

Cytochrome b Species A and B

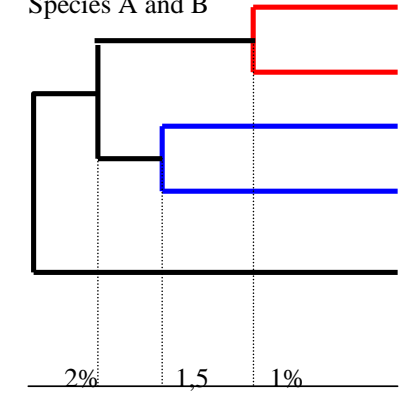

a)
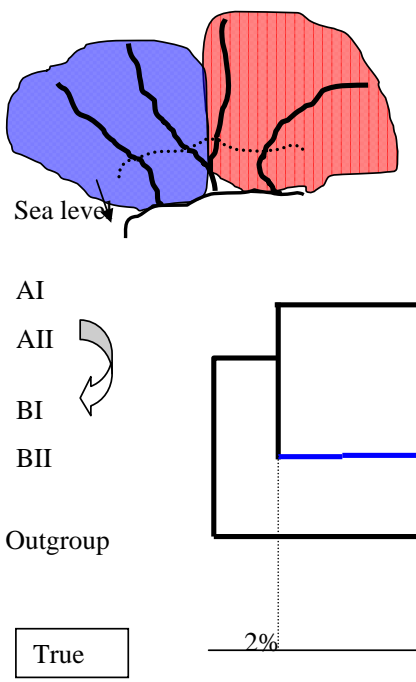

Fig. (3). Impact of hybridisation phenomena on time divergence estimation. (a) We consider two species A and B constituted by two lineages I and II. The arrow indicated the mitochondrial introgression of species AII on species BI. (b) The result is that species BI is very close to AII. (c) With stochastic extinction of lineages, one can underestimate the true divergence between the two lineages AI and BI. The use of multiple molecular markers will be necessary.
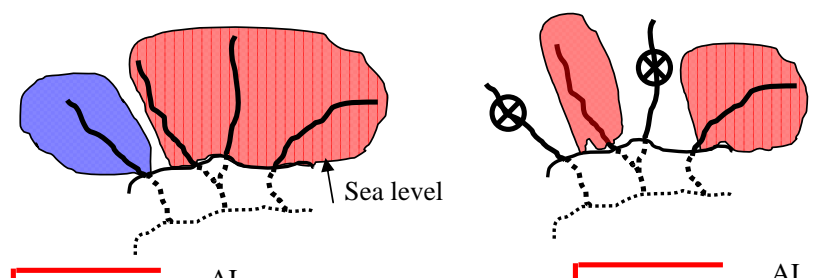

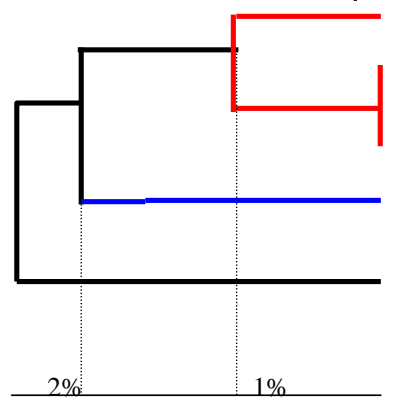

b)
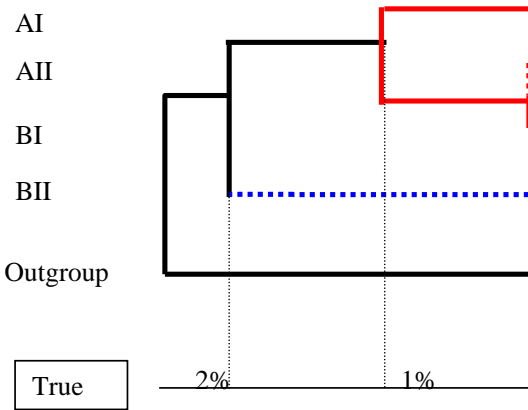

c)

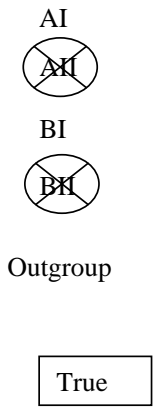

rue 

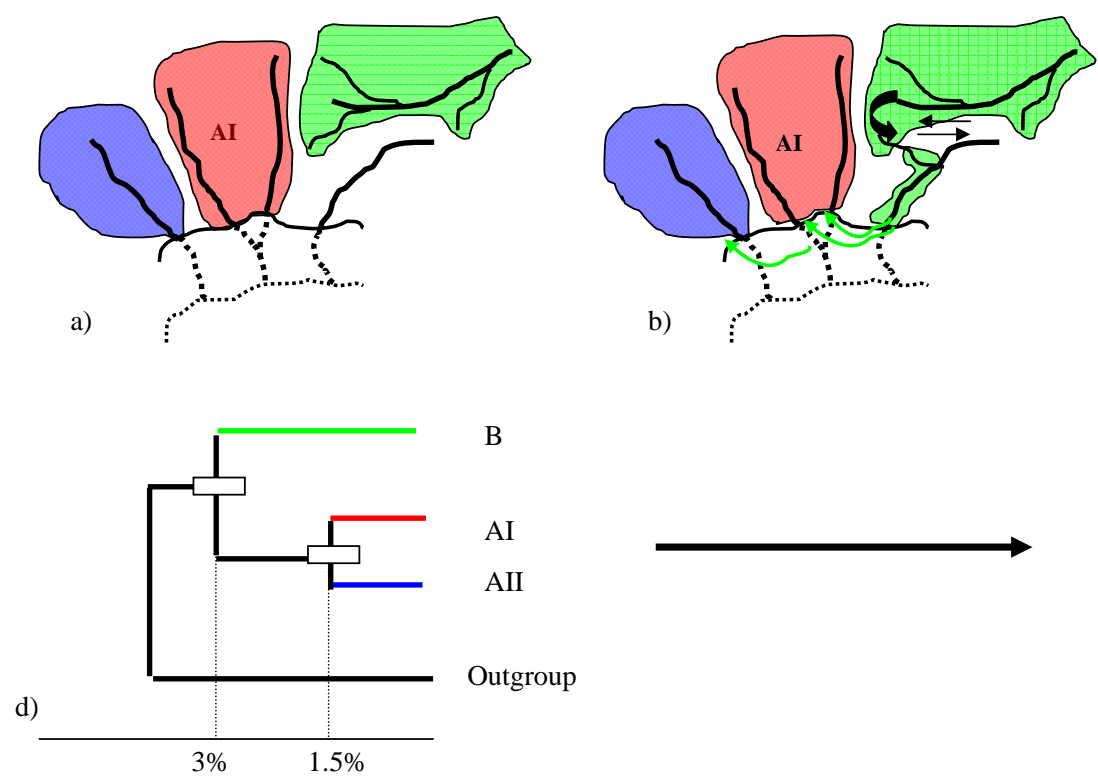

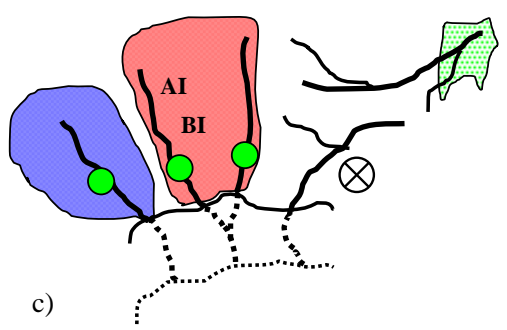

c)

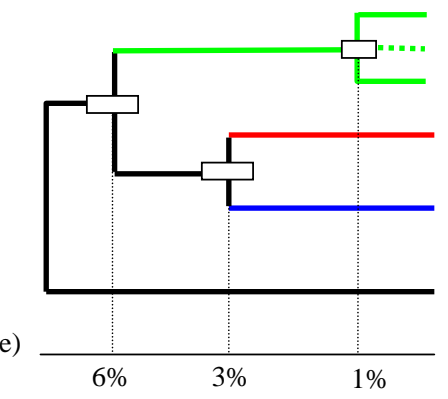

BI

BIII

BII

AI

AII

Outgroup

Fig. (4). Inferring evolutionary history and colonisation pattern of two species. The geographic schemes represent the distribution of two species of a same genus with different ecological behaviour front of water salinity . a) The distribution area of the species A (constituting by two lineages AI and AII) is different from the second species (B). b) Basins capture phenomenon and rivers connection added to the migration behaviour of the species B allowed the colonisation of the species A distribution area by the sea. c) Then, following different events, the origin geographic area of the species B tends to disappear and the BI and BII lineages evolved and lost their salinity tolerance. d) and e) Trying to infer this evolutionary history using molecular markers involve the use of the same marker for the two species and a non significant rate of substitution. Furthermore, the biological reconstruction of such a colonisation processes implies an adequate sampling (i.e. in the three different area), the knowledge of the geological events and of the ecological behaviour changes of the considered species.

hypothesis that ancestors of the different current representatives did not change their eco-physiologic behavior).

The two following points are more technical than conceptual.

Thus, the fifth potential artifact arises from choice of the distance used in the estimation of substitution pattern. Inferring phylogenetic relationships between taxa using DNA sequences imply first to verify and formalize a set of suppositions about the processes that have generated the observed sequences. For example, the choice of an evolutionary distance estimator is crucial on the inferred phylogeny. These are a variety of methods that measure the degree of difference between two molecules; whether that is two proteins or two DNA strands. We can cite some examples among the more cited: the p-distance is merely the proportion ( $\mathrm{p}$ ) of nucleotide sites at which the two sequences compared are different; the Juke-Cantor distance was developed under the assumption that the rate of nucleotide substitution is the same for all pairs of the four nucleotides A, T, C, and G; the Kimura 2 parameter distance makes it is possible to compute the numbers of transitional (s) and transversional $(\mathrm{v})$ nucleotide substitutions per site and their variances ; ...). Of course, the conclusion and discussion of phylogenetic reconstructions strongly depend of which distance is used.

Posada and Buckley [68] identify 203 "standard" timereversible models of nucleotide substitution and discussed the use of model selection versus usual LRT approaches. It is important to underline the Rhzetsky and Nei [69] work that proposed tests based on linear invariant for various models of nucleotide substitution independently of the phylogeny. But, choosing a common estimator for the whole data set involves the existence of a common process for the whole lineage. As pointed out by Kumar and Cadagkar [70], this has first to be tested and not just assumes, as well as the stationary of the base frequency [69].

Once the phylogeny is inferred, it is possible to investigate the different processes that have lead to the current observed pattern. The main underlying question is to evaluate the general causes of speciation (including random). Several methods have been proposed to estimate speciation and extinction rates [71-73]. As pointed out by Pybus et al. [74], tests of macro-evolutionnary models have to deal with the fact that phylogenies are incomplete (because by definition extents lineages are not present today), with the taxa sampling scheme [75] as well as with the taxonomic status.

The sixth difficulty is the estimated time of divergence between markers and lineages, (Fig. 5). Estimating timescales from genetic data is laden with methodological obstacles. Most important is the selection of an appropriate calibration, which is necessary for converting measures of genetic divergence into units of absolute or geological time. Calibrating information can be done by either fixing the age of a phylogenetic divergence event on the basis of independent palaeontological, archaeological, or biogeographic data; or importing a substitution rate obtained from independent data; or including into the data set sequences of known age, such as ancient DNA sequences extracted from 


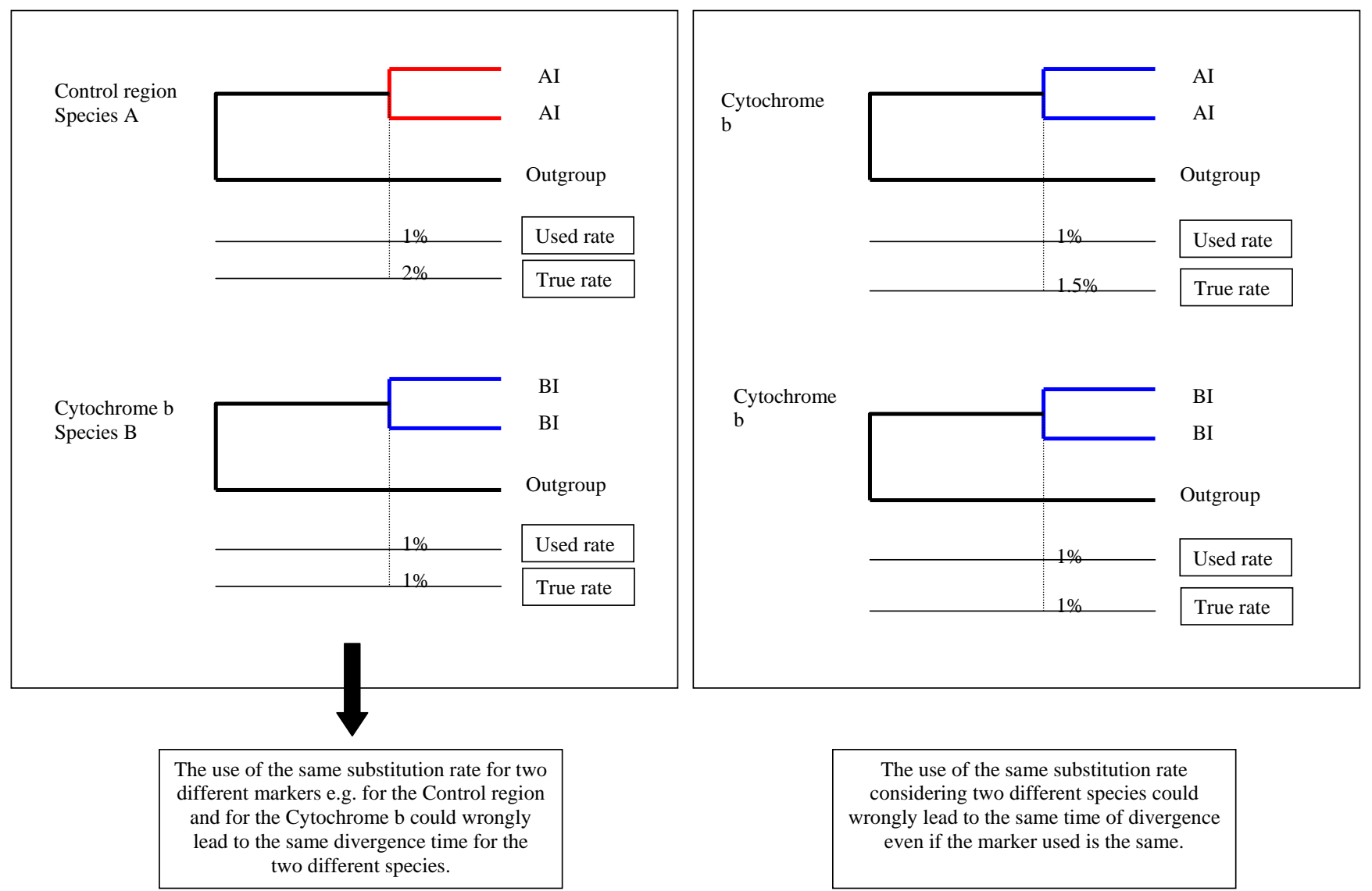

Fig. (5). Substitution rate and divergence time. Illustration of the miss use of substitution rate in the estimating of divergence time between i) two different markers (left part), ii) two different species (right part).

radiocarbon-dated samples. Thus, the comparison across taxa and marker necessitates a standardisation of molecular clock calibration. Mitochondrial DNA is the classical marker used in phylogeography, but different regions of the molecule were analyzed (cytochrome b, Control region and so on...). The rate of substitution between these regions and/or between species could be significantly different.

Indeed, some multi-taxa studies have reported substantial interspecific variation in mtDNA substitution rate [76]. The relative consistency of the rate at which sequences evolve is not so obvious. Ho and Carson [77] demonstrated that there is indeed an acceleration of molecular evolution on short time scales for primate and bird (in Penny [78]). The observed rate at which molecular clock "ticks" is not entirely constant over time [77].

Furthermore, it is important to underline that studies can consider global molecular clock or local molecular clocks with one or several calibration points. The consequences of such choice could have a huge impact on the time divergence estimated. In such a circumstance, it is crucial that biologists be critical about the choice of molecular clock and do not use "known rate" without asking if it is adaptable to their biological model. Before performing meta-analysis is it obvious that coherent data sets (coherent genes, test of molecular clock...) have to be compiled before extracting global patterns.
Finally, the last point involving freshwater biological models, is the river capture and river reversal that constituted historical changes in riverine connections. The displacement of tributaries or stream section between adjacent catchment areas defines the river capture. This geologic kinetic involves a mix of different populations (or species) that were previously isolated. River reversal induces a new drainage division that produces an isolated population, which previously inhabited the same system [79]. These two types of river displacement represent precise spatial and temporal disruptions of linear systems. As highlighted by Page [80], these two patterns constituted two hypotheses testable with or without well-calibrated molecular clocks.

\section{CONCLUSION}

The increasing richness and amount of information supplied by the numerous studies of phylogeography allowed the comparison of evolutionary processes between different taxa. The emergence of this idea "to compare phylogeography " and the forerunner of these informative potentialities were notably presented by Bermingham and Moritz [81]. However, the bibliographic data showed the difficulties in the present state of the art to generalise biological conclusions of colonisation patterns notably for European freshwater. Indeed, we notice that the Iberian (Spain and Portugal) and Apulean (Italia) peninsulas were the refuge zone for many sister species [82, 83] of the different "large repartition species" described above underlying an ongoing colonisation process for freshwater 
fish. The results presented here particularly illustrate the doubt linked to the time divergence estimation of colonisation events, the pattern of dispersal, the presence of more refuge zones than previously thought, the evolutionary importance played by hybridization phenomenon in the population structuring, dispersal and the understanding of gene flow between different lineages.

All these studies plus the potential artifacts we developed here, highlight the need to study more markers (mtDNA, nuclear DNA, morphological data) and more species [84]. Some studies began to develop an integrative approach combining several markers and environmental data e.g. in Salducci et al. [85]. However, future studies need to take into account all the parameters developed in this study in the elaboration of comparative phylogeography [81, 49] to decipher the complex pattern of freshwater fish in particular, but also for other biological models. It is important to notice that for some biological or methodological points there is no universal solution. Nevertheless, knowledge of potential bias remains the better weapon not to infer wrong biological process or pattern and to solicited cautious conclusion.

These problematic biases represent new challenges notably for the development of more appropriate biodiversity conservation strategies. Indeed, while it has been acknowledged that long term information should be routinely incorporated in conservation planning, successful examples remain quite rare. Some recent studies (reviewed in Froyd and Willis [86]) presented the need of palaeoecological approach as emerging issue in biodiversity and conservation management. The interest of such an approach is multiple as in the determination of reference and natural ecosystem variability or in the determination of baselines of former species distributions and abundance. Furthermore, understanding colonization processes and diversification rates present other benefits notably in a context of biological invasion with the determination of natural ranges of species and their evolution over time. A long temporal record can provide important data for predicting future impacts of invasive species under changing climate. Finally, as Froyd and Willis pointed out "the intent of this type of analysis is not, as is commonly perceived, to dictate the re-creation of past ecosystem conditions, but rather to form an objective, scientific basis on which to base conservation activities -or to soundly assess the trade-offs if alternate goals are to be implemented."

\section{ACKNOWLEDGMENT}

We greatly thank Bernd Hänfling for rich discussions and helpful comments on our manuscript and for rereading help. We thank Nicolas Pech for methodological discussions and Jonathan Scott for correction of our English usage.

\section{REFERENCES}

[1] Bernatchez L, Wilson CC. Comparative phylogeography of nearctic and palearctic fishes. Mol Ecol 1998; 7: 431-52.

[2] Hewitt GM. Post-glacial re-colonization of European biota. Biol J Linn Soc 1999; 68: 87-112.

[3] Taberlet P, Fumagalli L, Wustsaucy AG, Cosson JF. Comparative phylogeography and postglacial colonization routes in Europe. Mol Ecol 1998; 7: 453-64.

[4] Hewitt GM. Genetic consequences of climatic oscillations in the Quaternary. Philos Trans Soc Lond B Biol Sci 2004; 359: 183-95.
[5] Stewart JR, Lister AM. Cryptic northern refugia and the origins of the modern biota. Trends Ecol Evol 2001; 16: 608-13.

[6] Lapointe FJ, Rissler LJ. Congruence, consensus, and the comparative phylogeography of codistributed species in California. Am Nat 2005; 166: 290-9.

[7] McDowall RM. What biogeography is: a place for process. J Biogeogr 2004; 31: 345-51. Morin PA, Luikart G, Wayne RK. SNPs in ecology, evolution and conservation. Trends Ecol Evol 2004; 19: 208-16.

[8] Van Houdt JK, Hellemans B, Volckaert FAM. Phylogenetic relationships among Palearctic and Nearctic burbot (Lota lota) Pleistocene extinctions and recolonization. Mol Phylogenet Evol 2003; 29: 599-612.

[9] Nesbo CL, Fossheim T, Vollestad LA, Jakobsen KS. Genetic divergence and phylogeographic relationships among European perch (Perca fluviatilis) populations reflect glacial refugia and postglacial colonization. Mol Ecol 1999; 8: 1387-404.

[10] Englbrecht CC, Freyhof J, Nolte A, Rassmann K, Schliewen U, Tautz D. Phylogeography of the bullhead Cottus gobio (Pisces: Teleostei: Cottidae) suggests a pre-Pleistocene origin of the major central European populations. Mol Ecol 2000; 9: 709-22.

[11] Volckaert FAM, Hanfling B, Hellemans B, Carvalho GR. Timing of the population dynamics of bullhead Cottus gobio (Teleostei: Cottidae) during the Pleistocene. J Evol Biol 2002; 15: 930-44.

[12] Kontula T, Vainola R. Molecular and morphological analysis of secondary contact zones of Cottus gobio in Fennoscandia: geographical discordance of character transitions. Biol J Linn Soc 2004; 81: 535-52.

[13] Slechtova V, Bohlen J, Freyhof J, Persat H, Delmastro GB. The Alps as barrier to dispersal in cold-adapted freshwater fishes? Phylogeographic history and taxonomic status of the bullhead in the Adriatic freshwater drainage. Mol Phylogenet Evol 2004; 33: 225-39.

[14] Weiss S, Persat H, Eppe R, Schlotterer C, Uiblein F. Complex patterns of colonization and refugia revealed for European grayling Thymallus thymallus, based on complete sequencing of the mitochondrial DNA control region. Mol Ecol 2002; 11: 1393-1407.

[15] Gum B, Gross R, Kuehn R. Mitochondrial and nuclear DNA phylogeography of European grayling (Thymallus thymallus): evidence for secondary contact zones in central Europe. Mol Ecol 2005; 14: 1707-25.

[16] Froufe E, Knizhin I, Weiss S. Phylogenetic analysis of the genus Thymallus (grayling) based on mtDNA control region and ATPase 6 genes, with inferences on control region constraints and broadscale Eurasian phylogeography. Mol Phylogenet Evol 2005; 34: 106-17.

[17] Culling MA, Janko K, Boron A, Vasil'ev VP, Cote IM, Hewitt GM. European colonization by the spined loach (Cobitis taenia) from Ponto-Caspian refugia based on mitochondrial DNA variation. Mol Ecol 2006; 15: 173-190.

[18] Šediva A, Janko K, Šlechtovaal V, et al. Around or across the Carpathians: colonization model of the Danube basin inferred from genetic diversification of stone loach (Barbatula barbatula) populations. Mol Ecol 2008; 17: 1277-92.

[19] Machordom A, Doadrio I, Berrebi P. Phylogeny and evolution of the genus Barbusin the Iberian Peninsula as revealed by allozyme electrophoresis. J Fish Biol 1995; 47: 211-36.

[20] Zardoya R, Doadrio I. Phylogenetic relationships of Iberian cyprinids: systematic and biogeographical implications. Proc R Soc Lond B Biol Sci 1998; 265: 1365-72.

[21] Tsigenopoulos CS, Berrebi P. Molecular phylogeny of north mediterranean freshwater barbs (genus Barbus: Cyprinidae) inferred from cytochrome $b$ sequences: biogeographic and systematic implications. Mol Phylogenet Evol 2000; 14: 165-79.

[22] Machordom A, Doadrio I. Evidence of a cenozoic Betic-Kabilian connection based on freshwater fish phylogeography (Luciobarbu: Cyprinidae). Mol Phylogenet Evol 2001a; 18: 252-63.

[23] Machordom A, Doadrio I. Evolutionary history and speciation modes in the cyprinid genus Barbus. Proc R Soc B-Biol Sci 2001b; 268: $1297-306$

[24] Kotlik P, Berrebi P. Phylogeography of the barbel (Barbus barbus) assessed by mitochondrial DNA variation. Mol Ecol 2001; 10: 2177-85.

[25] Kotlik P, Berrebi P. Genetic subdivision and biogeography of the Danubian rheophilic barb Barbus petenyi inferred from 
phylogenetic analysis of mitochondrial DNA variation. Mol Phylogenet Evol 2002; 24: 10-18.

[26] Tsigenopoulos CS, Kotlik P, Berrebi P. Biogeography and pattern of gene flow among Barbus species (Teleostei: Cyprinidae) inhabiting the Italian Peninsula and neighbouring Adriatic drainages as revealed by allozyme and mitochondrial sequence data. Biol J Linn Soc 2002; 75: 83-99.

[27] Tsigenopoulos CS, Durand JD, Unlu E, Berrebi P. Rapid radiation of the Mediterranean Luciobarbus species (Cyprinidae) after the Messinian salinity crisis of the Mediterranean Sea, inferred from mitochondrial phylogenetic analysis. Biol J Linn Soc 2003; 80: 207-22.

[28] Crespin L, Berrebi P, Lebreton J-D. Asymmetrical introgression in a freshwater fish hybrid zone as revealde by a morphological index of hybridization. Biol J Linn Soc 1999; 67: 57-72.

[29] Durand JD, Persat H, Bouvet Y. Phylogeography and postglacial dispersion of the chub (Leuciscus cephalus) in Europe. Mol Ecol 1999a; 8: 989-97.

[30] Durand JD, Templeton AR, Guinand B, Imsiridou A, Bouvet Y. Nested clade and phylogeographic analyses of the chub, Leuciscus cephalus (Teleostei, Cyprinidae), in Greece: Implications for Balkan Peninsula biogeography. Mol Phylogenet Evol 1999b; 13: 566-80.

[31] Durand JD, Unlu E, Doadrio I, Pipoyan S, Templeton AR. Origin, radiation, dispersion and allopatric hybridization in the chub Leuciscus cephalus. Proc R Soc B-Biol Sci 2000; 267: 1687-97.

[32] Sanjur OI, Carmona JA, Doadrio I. Evolutionary and biogeographical patterns within Iberian populations of the genus Squalius inferred from molecular data. Mol Phylogenet Evol 2003; 29: $20-30$

[33] Orti G, Bell MA, Reimchen TE, Meyer A. Global survey of mitochondrial-DNA sequences in the threespine stickleback Evidence for recent migrations. Evolution 1994; 48: 608-22.

[34] Gilles A, Chappaz R, Cavalli L, Lortscher M, Faure E. Genetic differentiation and introgression between putative subspecies of Leuciscus sonfia (Teleostei: Cyprinidae) of the region of the Mediterranean Alps. Can J Fish Aquat Sci 1998; 55: 2341-54.

[35] Salzburger W, Brandstatter A, Gilles A, et al. Phylogeography of the vairone (Leuciscus souffia, Risso 1826) in Central Europe. Mol Ecol 2003; 12: 2371-86.

[36] Ketmaier V, Bianco PG, Cobolli M, Krivokapic M, Caniglia R, De Matthaeis E. Molecular phylogeny of two lineages of Leuciscinae cyprinids (Telestes and Scardinius) from the peri-Mediterranean area based on cytochrome $b$ data. Mol Phylogenet Evol 2004; 32: 1061-71.

[37] Stefani F, Galli P, Zaccara S, Crosa G. Genetic variability and phylogeography of the cyprinid Telestes muticellus within the Italian peninsula as revealed by mitochondrial DNA. J Zool Syst Evol Res 2004; 42: 323-31.

[38] Bianco P. Potential role of the palaeohistory of the Mediterranean and Paratethis basins on the early dispersal of Euro-Mediterranean freshwater fishes. Ichthyol Explor Freshwaters 1994; 167-184.

[39] Costedoat C, Chappaz R, Barascud B, Guillard O, Gilles A. Heterogeneous colonization pattern of European Cyprinids, as highlighted by the dace complex (Teleostei: Cyprinidae). Mol Phylogenet Evol 2006; 41: 127-48.

[40] Durand JD, Bianco PG, Laroche J, Gilles A. Insight into the oigin of endemic mediterranean ichthyofauna: phylogeography of Chondrostoma Genus (Teleostei, Cyprinidae). J Hered 2003; 94: 315-328.

[41] Doadrio I, Carmona JA. Phylogenetic relationships and biogeography of the genus Chondrostoma inferred from mitochondrial DNA sequences. Mol Phylogenet Evol 2004; 33: 802-15.

[42] Nelva-Pasqual A. Origine et biogéographie des deux Chondrostomes Français: Chondrostoma nasus et C. toxostoma (Pisces, Cyprinidae). Cybium 1988; 12: 287-299.

[43] Robalo J, Almada VC, Levy A, Doadrio I. Re-examination and phylogeny of the genus Chondrostoma based on mitochondrial and nuclear data and the definition of 5 new genera. Mol Phylogenet Evol 2007; 42: 362-72.

[44] Costedoat C, Pech N, Salducci MD, Chappaz R, Gilles A. Evolution of mosaic hybrid zone between invasive and endemic species of Cyprinidae through space and time. Biol J Linn Soc 2005; 85: 1-20.
[45] Costedoat C, Pech N, Chappaz R, Gilles A. Novelties in hybrid zones: crossroads between population genomic and ecological approaches. PLoS ONE 2007; 2: e357. doi number 10.1371/ journal.pone.0000357.

[46] Bohlen J, Šlechtova V, Bogutskaya N, Freyhof J. Across Siberia and over Europe: Phylogenetic relationships of the freshwater fish genus Rhodeus in Europe and the phylogenetic position of R. sericeus from the River Amur. Mol Phylogenet Evol 2006; 40: 85665.

[47] Costedoat C, Pech N, Chappaz R, Salducci D, Lim P, Gilles A. Study of introgressive hybridization between Chondrostoma $t$. toxostoma and Chondrostoma n. nasus (Teleostei, Cyprinidae) using multiple approaches. Cybium 2004; 28: 51-61.

[48] Hänfling B, Hellemans B, Volkaert FAM, Carvalho GR. Late glacial history of the cold-adapted freshwater fish Cottus gobio, revealed by microsatellites. Mol Ecol 2002; 11: 1717-29.

[49] Avise JC. Phylogeography: The History and Formation of species. Cambridge, MA: Harvard University Press 2000.

[50] Brito PH. The influence of Pleistocene glacial refugia on tawny owl genetic diversity and phylogeography in western Europe. Mol Ecol 2005; 14: 3077-94.

[51] Hewitt GM. The genetic legacy of the Quaternary ice ages. Nature 2000; 405: 907-913.

[52] Moritz C, Richardson KS, Ferrier S, et al. Biogeographical concordance and efficiency of taxon indicators for establishing conservation priority in a tropical rainforest biota. Proc R Soc BBiol Sci 2001; 268: 1875-81.

[53] Brumfield RT, Beerli P, Nickerson DA, Edwards SV. The utility of single nucleotide polymorphisms in inferences of population history. Trends Ecol Evol 2003; 18: 249-56.

[54] Hare MP. Prospects for nuclear gene phylogeography. Trends Ecol Evol 2001; 16: 700-6.

[55] Morin PA, Luikart G, Wayne RK. Applications of single nucleotide polymorphisms (SNPs) in ecology, evolution, and conservation. Trends Ecol Evol, 2004; 19: 208-16.

[56] Knowles LL. The burgeoning field of statistical phylogeography. J Evol Biol 2004; 17: 1-10.

[57] Knowles LL, Maddison WP. Statistical phylogeography. Mol Ecol 2002; 11: 2623-2635.

[58] Lapointe FJ, Rissler LJ. Congruence, consensus, and the comparative phylogeography of codistributed species in California. Am Nat 2005; 166: 290-9.

[59] Wakeley J. Recent trends in population genetics: More data! More math! Simple models? J Hered 2004; 95: 397-405.

[60] Doyle JJ. Trees within trees: genes and species, molecules and morphology. Syst Biol 1997; 46: 537-53.

[61] Maddison WP. Gene trees in species trees. Syst Biol 1997; 46: $523-$ 536.

[62] Nichols R. Gene trees and species trees are not the same. Trends Ecol Evol 2001; 16: 358-64.

[63] Wiens JJ, Donoghue MJ. Historical biogeography, ecology and species richness. Trends Ecol Evol 2004; 19: 639-44.

[64] Gomez-Zurita J, Vogler AP. Incongruent nuclear and mitochondrial Phylogeographic Patterns in the Timarcha goettingensis Species Complex (Coleoptera, Chrysomelidae). J Evol Biol 2003; 16: 833-43.

[65] Wiens JJ. The role of morphological data in phylogeny reconstruction. Syst Biol 2004; 53: 653-61.

[66] Wiens JJ. Character analysis in morphological phylogenetics: Problems and solutions. Syst Biol 2001; 50: 689-99.

[67] Banarescu P. Zoogeography of freshwater. General distribution and dispersal of freshwaters animals. Wiesbaden: Aula Verlag 1990; Vol. 1.

[68] Posada D, Buckley T. Model selection and model averaging in phylogenetics : advantages of akaïke information criterion and bayesian approaches over likelihood ratio tests. Syst Biol 2004; 53: 793-808.

[69] Rzhetsky A, Nei M. Tests of applicability of several substitution models for DNA sequence data. Mol Biol Evol 1995; 12: 131-51.

[70] Kumar S, Gadagkar SR. Disparity index: a simple statistic to measure and test the homogeneity of substitution patterns between molecular sequences. Genetics 2001; 159: 913-4.

[71] Nee S, May RM, Harvey PH. The reconstructed evolutionary process. Philos Trans R Soc Lond B 1994; 344: 305-11. 
[72] Nee S, Holmes CE, Rambault A, Harvey PH. Inferring population history from molecular phylogenies. Philos Trans R Soc Lond B 1995; 349: 25-31.

[73] Barraclough TG, Nee S. Phylogenetics and speciation. Trends Ecol Evol 2001; 16: 391-9.

[74] Pybus OG, Harvey PH. Testing macro-evolutionary models using incomplete molecular phylogenies. Proc R Soc Lond B 2000; 267: 2267-72.

[75] Pybus OG, Rambaut A. New inferences from tree shape: number of missing taxa and population growth rates. Syst Biol 2002; 51: 8818.

[76] Bermingham E, McCafferty S, Martin A. Fish biogeography and molecular clocks: perspectives from the Panamanian Isthmus. In: Kocher T, Stepien C, Eds. Molecular Systematics of Fishes, NY, USA: Academic Press 1997; pp. 113-126.

[77] Ho SYW, Larson G. Molecular clocks: when times are a-changin'. Trends Genet 2006; 22: 79-83.

[78] Penny D. Relativity for Molecular Clocks. Nature 2005; 436: $183-$ 4.

[79] Waters JM, Rowe DL, Apte S, et al. Geological dates and molecular rates: rapid divergence of rivers and their biotas. Syst Biol 2007; 57: 271-82.
[80] Page RDM. New Zealand and the new biogeography. NZJ Zool 1989; 16: 471-83.

[81] Bermingham E, Moritz C. Comparative phylogeography: concepts and applications. Mol Ecol 1998; 7: 367-9.

[82] Mesquita N, Cunha C, Carvalho GR, Coelho MM. Comparative phylogeography of endemic cyprinids in the south-west Iberian Peninsula: evidence for a new ichthyogeographic area. J Fish Biol 2007; 71: 45-75.

[83] Reyjol Y, Hugueny B, Pont D, et al. Patterns in species richness and endemism of European freshwater fish. Global Ecol Biogeogr 2007; 16: 65-75.

[84] Stone G. Phylogeography, hybridization and speciation. Trends Ecol Evol 2000; 15: 354-5.

[85] Salducci MD, Martin JF, Pech N, Chappaz R, Costedoat C, Gilles A. Deciphering the evolutionary biology of freshwater fish using multiple approaches - insights for the biological conservation of the Vairone (Leuciscus souffia souffia). Conserv Genet 2004; 5: 63-78.

[86] Froyd CA, Willis KJ. Emerging issue in biodiversity and conservation management: the need for a paleaecological perspective. Quat Sci Rev 2008; 27: 1723-32.

Received: March 31, $2008 \quad$ Revised: March 21, $2009 \quad$ Accepted: April 10, 2009

(C) Costedoat and Gilles; Licensee Bentham Open.

This is an open access article licensed under the terms of the Creative Commons Attribution Non-Commercial License (http://creativecommons.org/licenses/by-nc/3.0/) which permits unrestricted, non-commercial use, distribution and reproduction in any medium, provided the work is properly cited. 